\title{
REALOKASI PEGAWAI SEBAGAI SALAH SATU UPAYA PENGEMBANGAN KARIER
}

\author{
M. Takdir Mulyadi ${ }^{1}$
}

\begin{abstract}
Article clarifies a procedure of staff reallocation with a case study at the agency of Agricultural Research and Dvelopment. It present the idea of reallocation, problems, objectives, methodology, the present staff condition concerning staff composition, research policy, goal target, and its constraints as well as policy and activies to solve them.
\end{abstract}

Keywords: staff reallocation, staff development program

\section{ABSTRAK}

Artikel memaparkan prosedur realokasi pegawai dengan studi kasus pada pegawai Badan Penelitian dan Pengembangan Pertanian. Dalam artikel ini dijelaskan tentang realokasi, masalah, tujuan penelitian, metodologi, kondisi pegawai saat ini berkaitan dengan komposisi staf, kebijakan penelitian, sasaran, dan pemecahan masalah.

Kata kunci: realokasi pegawai, pengembangan karir

\footnotetext{
${ }^{1}$ Staf Pengajar Fakultas Ekonomi, UBiNus, Jakarta
} 


\section{PENDAHULUAN}

\section{Latar Belakang}

Badan Penelitian dan Pengembangan (Badan Litbang) Pertanian mempunyai mandat mengembangkan Ilmu Pengetahuan dan Teknologi (IPTEK) yang diperlukan untuk pembangunan pertanian melalui program penelitian pertanian. Penelitian pertanian merupakan bagian integral dari pembangunan nasional dan berperan menyediakan landasan IPTEK yang mampu memberikan umpan ke depan bagi pembangunan pertanian dalam arti luas.

Badan Litbang Pertanian dibentuk tahun 1974 melalui Keputusan Presiden Republik Indonesia No.44 tahun 1974 tentang Pokok Organisasi Departemen Pertanian dan Keppres Nomor: 45/1974 tentang Susunan Organisasi Departemen Pertanian. Untuk mengimbangi dinamika pembangunan, oganisasi Departemen Pertanian dan Badan Litbang Pertanian telah beberapa kali mengalami penyempurnaan dan terakhir ditetapkan dengan Keppres Nomor 355/M tahun 1999 yang ditindaklanjuti dengan Keputusan Menteri Pertanian Nomor: 1016/Kpts/Ot.210/12/98. Pusat Penelitian Sosial Ekonomi Pertanian (PSE) memiliki 11 Balai Pengkajian Teknologi Pertanian (BPPT) dan 6 Loka Pengkajian Teknologi Informasi (LPPT). Hal itu tertuang dalam Serat Keputusan Menteri Pertanian No.798/Kpts/OT.210/12/94 tanggal 13 Desember 1994 tentang Organisasi dan Tata Kerja Balai Pengkajian Teknologi Pertanian dan Loka Pengkajian Teknologi Pertanian (BPTP/LPTP). BPTP/LPTP merupakan Unit Pelaksana Teknis (UPT) Badan Litbang Pertanian yang mempunyai kedudukan sangat strategis karena ujung tombak Badan Litbang yang secara langsung berhubungan dengan user (petani) pengguna teknologi yang diahasilkan Badan Litbang Pertanian.

Menyongsong era perdagangan bebas nanti, Badan Litbang Pertanian mempunyai tugas yang sangat strategis. Teknologi yang dihasilkan harus mampu mendukung persaingan dalam era globalisasi perdagangan. Disadari Sumber Daya Manusia (SDM) memegang peranan sangat penting dan merupakan salah satu kesusesan Badan Litbang Pertanian. Oleh karena itu, perlu strategi dalam pengelolaan aset, khususnya SDM Badan Litbang Pertanian. Penguasaan informasi teknologi merupakan keharusan agar lembaga penelian menghasilkan inovasi teknologi yang bersifat terobosan dan menghasilkan produk yang berdaya saing tinggi sesuai dengan kebutuhan konsumen yang senantiasa berubah. Dalam hal ini, peran serta SDM (Sumber Daya Manusia) yang andal sangat diperlukan.

Pembinaan dan pengembangan Sumber Daya Manusia merupakan keharusan untuk dilaksanakan agar semakin tanggap terhadap permintaan teknologi yang diperlukan dalam pembangunan pertanian. Oleh karena itu, pembinaan karier pegawai perlu mendapat perhatian agar setiap pegawai mempunyai keahlian dalam bidangnya saat dikembangkan melalui jabatan fungsional. Meskipun ada keterbatasan dalam hal peneliti dan pembatasan penerimaan pegawai baru, pemindahan (realokasi) tenaga ke BPTPT/LPTP tetap masih diperlukan kesinambungannya. Mengingat masih belum seimbangnya penyebaran tenaga di setiap BPTP/LPTP lebih baik dari jumlah disiplin ilmunya. 


\section{Masalah Pokok}

Berkaitan dengan visi Badan Litbang Pertanian, yaitu sebagai lembaga penelitian, pengkajian, dan pengembangan pertanian yang proaktif dan partisipatif mampu menemukan dan merekayasa paket teknologi dan kerja sama sektor pertanian yang komprehensif pada masa mendatang dapat diidentifikasikan beberapa masalah pokok, yaitu belum optimalnya pelaksanaan tugas dan fungsi BPTP/LPTP. Hal itu disebabkan beberapa hal sebagai berikut.

1. Sarana dan prasarana yang kurang memadai.

2. Rendahnya jumlah tenaga yang berdisiplin ilmu sosial ekonomi.

3. Rendahnya pemahaman terhadap peraturan dan Kebijakan yang berkaitan dengan 3 M.

Dari ketiga penyebab masalah pokok di atas yang mendapat prioritas dalam pemecahannya adalah rendahmya jumlah tenaga yang disiplin ilmu sosial ekonomi pertanian pada BPTP/LPTP.

\section{Metode Pengumpulan Data}

1. Data Sekunder

a. studi kepustakaan

b. penelusuran dokumen/laporan

2. Data primer

a. pengalaman kerja penulis di Badan Litbang Pertanian

b. hasil konsultasi

\section{Lingkup Bahasan dan Pengertian}

Dalam rangka pencapaian visi dan misi Badan Litbang Pertanian di masa yang akan datang dapat diidentifikasikan permasalahan umum yang dihadapi, yaitu belum optimalnya pencapaian hasil penelitian sosial ekonomi pertanian karena unit pelaksana teknis (UPT) di lingkungan pusat penelitian sosial ekonomi pertanian masih baru. Dalam hal ini, faktor penyebab yang dianggap dominan dan menyebabkan belum optimalnya kinerja (PSE) adalah rendahnya jumlah tenaga yang berdisiplin ekonomi pertanian pada BPTP/LPTP.

Dalam penelitian ini dijumpai beberapa istilah dengan pengertian sebagai berikut.

1. Badan Penelitian dan Pengembangan Pertanian adalah unsur penunjang Departemen Pertanian di bidang penelitian dan pengembangan pertanian yang di bawah dan bertanggung jawab langsung kepada Menteri Pertanian.

2. Lembaga Penelitian dan Pengembangan yang proaktif dan partisipatif adalah lembaga penelitian yang mampu menemukan dan merekayasa paket teknologi dan Kebijakan pertanian yang komprehensif. 
3. Jabatan fungsional adalah jabatan yang tidak jelas disebut atau digambarkan dalam struktur organisasi. Akan tetapi, harus ada karena fungsinya yang memungkinkan kelancaran tugas organisasi itu.

4. Datasering adalah perbantuan tenaga dari unit kerja Badan Litbang Pertanian yang berdasarkan dengan lokasi unit kerja yang membutuhkan.

5. Formasi pegawai baru adalah jumlah dan susunan pangkat Pegawai Negeri Sipil yang diperlukan satuan organisasi negara agar mampu melaksanakan tugas pokok jangka waktu yang ditetapakn pejabat yang berwenang.

\section{PEMBAHASAN}

\section{Kondisi Saat Ini}

Penyebaran pegawai pada unit kerja lingkup Badan Litbang Pertanian, khususnya BPTP/LPTP belum merata. Walaupun sudah diadakan dua kali regrouping pegawai, yaitu dengan cara memindahkan pegawai dari tempat yang berlebihan jumlah pegawainya ke tempat yang kekurangan jumlah pegawainya. Pemindahan pegawai, khususnya ke luar Jawa untuk pemenuhan kebutuhaan tenaga di BPTP/LPTP masih menghadapi kendala, antara lain kesiapan yang bersangkutan untuk dimutasikan.

\section{Komposisi Tenaga}

Komposisi tenaga Badan Litbang Pertanian berdasarkan tingkat pendidikannya dapat dilihat pada tabel di bawah ini.

Tabel 1 Komposisi Pegawai Litbang Pertanian menurut Tingkat Pendidikannya Keadaan sampai dengan Desember 1996*)

\begin{tabular}{crrrr}
\hline TK. PENDIDIKAN & $\mathbf{1 9 7 5}$ & $\mathbf{1 9 8 5}$ & $\mathbf{1 9 9 5}$ & $\mathbf{1 9 9 6}$ \\
\hline S3 & 7 & 82 & 258 & 276 \\
\hline S2 & 26 & 282 & 722 & 738 \\
\hline S1 & 243 & 912 & 1974 & 1994 \\
\hline SM & 170 & 333 & 513 & 485 \\
\hline SLTA & 459 & 2074 & 3360 & 3374 \\
\hline SLTP & 215 & 282 & 308 & 302 \\
\hline SD & 2458 & 1485 & 1168 & 914 \\
\hline Jumlah & 3600 & 5450 & 8162 & 8110 \\
\hline
\end{tabular}

Sumber: SIM Kepegawaian Badan Litbang Penelitian

Dari tabel di atas terlihat Badan Tenaga Litbang Pertanian saat ini telah berkembang pesat sejak awal dibentuknya Badan Litbang Pertanian. Sebagai pelaku IPTEK, sumber daya manusia Badan Litbang Pertanian dituntut untuk bekerja sesuai bidang tugas dan disiplin keilmuannya. Sehubungan dengan hal tersebut pada tabel di bawah ini disajikan komposisi tenaga Badan Litbang Pertanian menurut disiplin keilmuannya. 
Tabel 2 Komposisi Pegawai Badan Litbang Pertanian menurut Disiplin Keilmuannya Keadaan sampai dengan Desember 1999*)

\begin{tabular}{lrrrrr}
\hline \multicolumn{1}{c}{ Disiplin Ilmu } & \multicolumn{3}{c}{ Jumlah Pendidikan } & \multicolumn{1}{l}{ Jumlah } \\
\hline & S3 & \multicolumn{1}{c}{ S2 } & \multicolumn{1}{c}{ S1 } & SM & \\
\hline Agronomi/Budidaya & 69 & 221 & 661 & 55 & $1006(28,80 \%)$ \\
\hline Sosial Ekonomi/AE & 31 & 70 & 108 & 6 & $215(6,16 \%)$ \\
\hline Ilmu Peternakan & 49 & 84 & 154 & 4 & $291(8,33 \%)$ \\
\hline Ilmu Perikanan & 15 & 58 & 151 & 12 & $236(6,76 \%)$ \\
\hline Ilmu Tanah & 23 & 87 & 111 & 3 & $224(6,41 \%)$ \\
\hline Mekanisasi Pertanian & 7 & 14 & 43 & 5 & $69(1,67 \%)$ \\
\hline Bioteknologi & 4 & 1 & 6 & 1 & $12(0,34 \%)$ \\
\hline Pemulihan Tanaman & 22 & 30 & 32 & 1 & $85(2,43 \%)$ \\
\hline Hama dan Penyakit Tan & 38 & 74 & 89 & 2 & $203(5,81 \%)$ \\
\hline Komunikasi dan Perpustakaan & 0 & 18 & 13 & 115 & $146(4,18 \%)$ \\
\hline Statistika & 2 & 11 & 17 & 4 & $34(0,97 \%)$ \\
\hline Ilmu Komputer & 1 & 1 & 1 & 17 & $20(0,58 \%)$ \\
\hline Ilmu Sosial & 3 & 36 & 390 & 214 & $643(18,41 \%)$ \\
\hline Lain-lain & 12 & 33 & 218 & 46 & $309(8,85 \%)$ \\
\hline Jumlah & 276 & 738 & 1994 & 485 & $3493(100 \%)$ \\
\hline
\end{tabular}

Sumber: SIM Kepegawaian

Dari tabel di atas terlihat komposisi pegawai lingkup Badan Litbang Pertanian sebagian besar didominasi olah tenaga dengan disiplin ilmu Agronomi/Budidaya Pertanian. Sementara itu, disiplin ilmu lain, seperti Sosial Ekonomi Pertanian merupakan disiplin ilmu yang sangat diperlukan untuk menunjang kegiatan penelitian dan pengkajian pada BPTP/LPTP di samping jumlahnya yang relatif kecil juga penyebarannya yang kurang merata. Untuk mendukung operasionalisasi BPTP/LPTP, terutama kegiatan penelitian dan pengkajian spesifik lokasi maka komposisi pegawai di atas dianggap cukup kritis untuk waktu yang akan datang dan tenaga yang mempunyai rumpun disiplin ilmu sosial ekonomi pertanian dibutuhkan dalam jumlah yang cukup banyak. Kondisi tenaga yang berdisiplin ilmu sosial ekonomi pertanian pada BPTP/LPTP dapat dilihat pada tabel di bawah ini.

Tabel 3 Sebaran Tenaga yang Berdisiplin Ilmu Sosial Ekonomi Pertanian pada BPTP/LPTP

\begin{tabular}{lrrrrc}
\hline \multicolumn{1}{c}{ Unit Kerja } & \multicolumn{7}{c}{ Tingkat Pendidikan } \\
\cline { 2 - 7 } & S3 & S2 & S1 & SM & Jumlah \\
\hline \multicolumn{1}{c}{ BPTP Gedong Johar } & 0 & 1 & 2 & 0 & 3 \\
\hline BPTP Sukaramai & 0 & 0 & 7 & 2 & 9 \\
\hline BPTP Lembang & 0 & 0 & 8 & 0 & 8 \\
\hline BPTP Unggaran & 0 & 0 & 9 & 1 & 10 \\
\hline BPTP Karangploso & 0 & 2 & 8 & 1 & 11 \\
\hline BPTP Naibonat & 0 & 1 & 15 & 2 & 18 \\
\hline BPTP Palangkaraya & 0 & 0 & 16 & 0 & 16 \\
\hline BPTP Ambon & 0 & 1 & 4 & 0 & 5 \\
\hline
\end{tabular}


Tabel 3 Sebaran Tenaga yang Berdisiplin Ilmu Sosial Ekonomi Pertanian pada BPTP/LPTP (lanjutan)

\begin{tabular}{llllll}
\hline BPTP Kendari & 0 & 0 & 12 & 0 & 12 \\
\hline BPTP Padang Marpoyan & 0 & 0 & 4 & 0 & 4 \\
\hline BPTP Biromaru & 0 & 1 & 5 & 1 & 7 \\
\hline BPTP Banda Aceh & 0 & 0 & 2 & 0 & 2 \\
\hline
\end{tabular}

Pada Tabel 2, terlihat jumlah tenaga yang termasuk dalam disiplin ilmu sosial ekonomi pertanian berjumlah 215 orang. Namun, pada Tabel 3 terlihat tenaga yang berlatar belakang disiplin ilmu sosial ekonomi pertanian pada Balai/Loka Pengkajian berjumlah 118 orang sehingga sejumlah 97 orang tersebar pada Balai Penelitian/Loka Penelitian. Di samping itu, dari tabel di atas terlihat jumlah tenaga sosial ekonomi pertanian yang mendukung operasionalisasi BPTP/LPTP, khususnya yang berlokasi di luar pulau Jawa jumlahnya masih kurang memenuhi sehingga masih perlu dilakukan penambahan tenaga yang dapat dilakukan dengan alokasi tenaga yang terdapat pada Balai/Loka penelitian serta BPTP/LPTP yang berada di pulau Jawa. Di samping itu, dalam jangka panjang dapat juga dilakukan rekruitmen pegawai baru.

\section{Kebijakan Penelitian}

Berkaitan dengan visi Badan Litbang Pertanian pada abad 21 akan datang peran serta dari sumber daya manusia, khususnya pejabat fungsional akan terus ditingkatkan. Salah satu Kebijakan yang ditetapkan dalam rangka pencapaian tujuan penelitian adalah sumber daya manusia yang ikut berpartisipasi dalam rangka penelitian harus sesuai antara bidang tugas dengan disiplin ilmu lainnya.

Di samping itu, Kebijakan penelitian sosial ekonomi yang semula dapat dilakukan Pusat Penelitian dan pengembangan/Balai Penelitian mulai saat ini lebih dikonsentrasikan pada BPTP/LPTP di bawah binaan Pusat Penelitian Sosial Ekonomi Pertanian (PSE). Penelitian sosial ekonomi masih dapat dilakukan pada Puslit/Puslitbang/Bali dan terbatas pada penelitian dengan analisis skala mikro.

\section{Keadaan yang Diinginkan}

\section{Sasaran}

Berdasarkan masalah utama dan latar belakang masalah yang telah diuraikan di atas, selanjutnya dapat dikemukakan keadaan yang diinginkan berkaitan dengan pembinaan karier pejabat fungsional sosial ekonomi pertanian adalah tercapainya peningkatan jumlah tenaga pendukung penelitian sosial ekonomi pertanian yang optimal untuk mendukung kegiatan BPTP/LPTP.

Adapun hal yang perlu diperhatikan berkaitan dengan sasaran prioritas tersebut adalah kondisi tenaga yang mempunyai disiplin ilmu sosial ekonomi pertanian yang saat ini masih berada di pusat Penelitian/pusat penelitian dan Pengembangan/Balai Penelitian yang bersedia untuk dipindahkan serta kejelasan tugas dan fungsi kegiatan penelitian sosial ekonomi pertanian memungkinkan timbulnya motivasi bagi pejabat fungsional sosial ekonomi pertanian untuk lebih 
mengoptimalkan kemampuannya dan potensinya di tempat yang baru sehingga kinerja unit kerja yang baru (BPTP/LPTP) akan meningkat.

\section{Peningkatan Jumlah Tenaga di BPTP/LPTP}

Jumlah tenaga yang ideal untuk melaksanakan tugas dan fungsi unit kerja adalah relatif karena banyaknya berkaitan dengan unsur kemampuan dan keterampilan yang dimiliki pelaksana dalam kebersamaan. Demikian pula halnya dengan kegiatan penelitian sosial ekonomi pertanian, jumlah tenaga yang ideal untuk pencapaian hasil yang optimal (Critical Mass) masih relatif sifatnya karena berkaitan dengan cakupan kegiatan yang akan dilaksanakan, kemampuan pejabat fungsional sosial ekonomi pertanian, dan dukungan sarana dan prasarana.

Sesuai dengan Kebijakan, penelitian yang berlaku saat ini untuk kegiatan penelitian dengan cakupan sedang, idealnya dilakukan 3 orang peneliti senior dan 5 orang peneliti yunior. Jadi, memerlukan 8 orang tenaga peneliti untuk mencapai hasil penelitian yang optimal. Seperti yang terlihat pada Tabel 3, sebaran tenaga fungsional yang mempunyai latar belakang sosial ekonomi pertanian, ada beberapa BPTP/LPTP yang berlokasi di luar pulau Jawa masih berada di bawah critical mass yang diisyaratkan.

Kebijakan Zero Growth di tingkat nasional berdampak pada pengangkatan pegawai baru yang sangat terbatas sehingga peningkatan jumlah tenaga yang berdisiplin ilmu sosial ekonomi pertanian untuk mencapai critical mass merupakan langkah yang tidak mungkin diharapkan dalam waktu dekat ini. Diharapkan dengan Kebijakan penelitian sosial ekonomi pertanian yang lebih dikonsentrasikan pada BPTP/LPTP. Tenaga yang berdisiplin ilmu sosial ekonomi pertanian dan tersebar cukup banyak di Pusat Penelitian/Pusat penelitian dan Pengembangan/Balai Penelitian dapat dipindahkan ke BPTP/LPTP yang membutuhkan sehingga tercapai jumlah tenaga ideal untuk melaksanakan kegiatan penelitian di BPTP/LPTP.

\section{Pembinaan Jabatan Fungsional}

Agar tercapainya kelancaran dan peningkatan laju pengembangan riset dan teknologi, koordinasi dan sinkronisasi pelaksanaan berbagai tugas dan fungsi lembaga penelitian dan pengembangan diperlukan adanya pengelolaan dan pembinaan termasuk peningkatan kemampuan dan kekuatan sumber daya manusia. Dengan upaya itu, diharapkan tercapai pemenuhan kriteria bagi unit Litbang yang bersangkutan (Rifai, 1996).

Berdasarkan gambaran visi badan Litbang Pertanian, terlihat peran para pejabat fungsional adalah sangat penting dan strategis dalam penyelenggaraan tugas dan fungsi organisasi badan Litbang Pertanian. Oleh karena itu, pembinaan terhadap para pejabat fungsional perlu dilakukan secara insentif dan berkesinambungan. Dukungan layanan administrasi yang andal diperlukan guna pencapaian target pembinaan jabatan fungsional. Menurut Wirsanto, pembinaan sumber daya manusia termasuk di dalamnya pejabat fungsional, hendaknya dapat membawa kepada keadaan yang lebih baik, antara lain sebagai berikut.

a. Peningkatan efisiensi dan produktivitas kerja;

b. kesempatan tenaga untuk mengembangkan pengetahuan dan keterampilan;

c. suasana kerja yang kondusif. 


\title{
Masalah dan Pemecahannya
}

\author{
1. Identifikasi Masalah
}

Balai/Loka Pengkajian Teknologi Pertanian BPTP/LPTP merupakan unit kerja baru di lingkungan Badan Litbang Pertanian. Pembentukan BPTP/LPTP dimaksudkan agar transfer teknologi kepada petani/nelayan sebagai pengguna dapat berjalan dengan baik karena sebelumnya sering terjadi hambatan dalam hal transfer teknologi kepada user (petani/nelayan).

BPTP/LPTP merupakan peleburan dari unit kerja Badan Litbang Pertanian (Subbalai Penelitian, Kebun Percobaan, Kolam Percobaan dan Balai Informasi Pertanian). Pada saat awal pembentukannya, sumber daya manusia BPTP/LPTP berasal dari Balai Informasi Pertanian (BIP) dan Subbalai Penelitian sehingga jumlah tenaga fungsionalnya secara umum dapat dikatakan masih belum optimal karena sebagian besar tenaga fungsional seperti peneliti, perekayasa, teknisi penelitian dan perekayasaan tersebar di balai penelitian.

Rendahnya dukungan tenaga fungsional (jumlahnya) merupakan salah satu penyebab belum optimalnya kinerja BPTP/LPTP, di samping belum terbentuknya koordinasi yang kuat dari sumber daya manusia yang melebur. Di samping itu, keberhasilan kegiatan penelitian tidak hanya ditentukan jumlah tenaga fungsional peneliti yang memadai. Akan tetapi, juga sangat ditentukan jumlah tenaga fungsional peneliti dalam melaksanakan tugasnya. Tenaga pendukung kegiatan penelitian termasuk ke dalam jabatan fungsional Teknisi Litkayasa.

\section{Pemecahan Masalah}

Untuk memecahkan masalah pokok, yaitu rendahnya jumlah tenaga peneliti dan pembantu peneliti atau teknisi dengan disiplin ilmu sosial ekonomi pertanian pada BPTP?LPTP, dalam penelitian ini diajukan usulan kegiatan peningkatan jumlah tenaga yang berdisiplin ilmu sosial ekonomi pertanian pada BPTP/LPTP secara bertahap dengan memindahkan tenaga yang berdisiplin ilmu sosial ekonomi pertanian dan saat ini banyak terdapat pada balai penelitian, pusat penelitian dan pengembangan, dan tenaga teknisi yang akan membantu kegiatan penelitian.

Pemidahan itu dilakukan secara bertahap karena terbatasnya anggaran rutin pemerintah untuk membiayai pesangon pindah pegawai. Di samping itu, pelaksanaan pemindahan pegawai dapat berjalan dengan baik apabila adanya kemauan dari para pegawai untuk mutasi ke tempat baru. Kemauan pegawai untuk pindah sangat tergantung kepada prospek karier di masa yang akan datang dan sarana penunjang yang diberikan unit kerja barunya. Dengan pengalihan mandat untuk penelitian sosial ekonomi pertanian dari Balai Penelitian ke BPTP/LPTP. Namun, tenaga tersebut sebelum memutuskan untuk pindah juga harus mempertimbangkan masalah keluarga. Pertimbangan keluarga menunjukan sampai seberapa besar kebaikan dan keburukan kemungkinan dampak pemindahan tersebut terhadap kondisi kesejahteraan keluarganya (dalam arti luas). Pertimbangan keluarga ini menyangkut apakah dengan mutasi alih tugas tersebut kondisi keluarga akan menjadi semakin baik atau memburuk. Hal itu merupakan pertimbangan nonteknis yang perlu diperhatikan secara rasional oleh pengambil kebijakan dalam mutasi alih tugas tersebut. Dengan peningkatan jumlah tenaga sosial ekonomi pertanian pada BPTP/LPTP, khususnya BPTP/LPTP yang berlokasi di luar Jawa diharapkan akan dapat membantu lebih mengoptimalkan pelaksanaan tugas dan fungsi BPTP/LPTP tersebut. 


\section{Rencana Tindak Lanjut}

Berdasarkan Tabel 3 di atas terlihat beberapa BPTP/LPTP yang berlokasi di luar pulau Jawa masih terdapat kekurangan tenaga yang berdisiplin ilmu sosial ekonomi pertanian apabila mengacu kepada persyaratan minimal jumlah tenaga peneliti sosial ekonomi pertanian (critical mass). Untuk memenuhi standar critical mass, masih dibutuhkan tambahan sekitar 46 orang tenaga peneliti yang mempunyai latar belakang disiplin ilmu sosial ekonomi pertanian. Sementara itu, dari Tabel 2 terlihat jumlah tenaga yang mempunyai latar belakang pendidikan sosial ekonomi pertanian di tingkat badan Litbang Pertanian adalah sebanyak 215 orang (termasuk yang saat ini berada di BPTP/LPTP sebanyak 118 orang). Berarti jumlah tenaga yang potensial untuk dipindahkan adalah sebanyak 215 orang dikurangi 118 orang dan hasilnya 97 orang.

Tentunya pemindahan sebanyak maksimal 97 orang atau sekurang-kurangnya 46 orang bukan merupakan pekerjaan yang mudah untuk dilaksanakan karena hambatan teknis dan nonteknis seperti yang telah diuraikan di atas. Untuk itu, perlu perencanaan yang baik antara lain sebagai berikut.

a. Pernyataan Kesediaan Pindah

Untuk memperoleh kepastian dari tenaga yang berlatar belakang sosial ekonomi pertanian yang tersebar di balai penelitian untuk pindah ke BPTP/LPTP, perlu dilakukan sosialisasi kebijakan pemindahan SDM tersebut kepada para tenaga yang berlatar belakang pendidikan sosial ekonomi pertanian yang tersebar pada balai penelitian, pusat penelitian, dan pengembangan. Dalam sosialisasi, perlu dijelaskan kebijakan baru tersebut, pemindahan kegiatan penelitian sosial ekonomi pertanian dari Balit ke Balai/Loka Pengkajian, prospek kegiatan penelitian sosial ekonomi pertanian di masa yang akan datang. Pada akhir kegiatan sosialisasi, dilakukan pertanian di masa yang akan datang. Pada akhir kegiatan sosialisasi, dilakukan penyebaran formulir isian mutasi alih tugas yang akan digunakan sebagai acuan untuk perencanaan anggaran rutin maupun kegiatan keproyekan pada masing-masing BPTP/LPTP.

b. Perencanaan Biaya Pesangon Pindah

Dari formulir isian yang telah terkumpul dilakukan verifikasi dan selanjutnya menyusun jumlah anggaran biaya pindah untuk masing-masing tenaga yang dipindahkan beserta keluarganya. Hal itu perlu dilakukan mengingat sifat mutasi alih tugas tersebut adalah karena dinas sehingga seluruh biaya pindah dibebankan kepada anggaran rutin badan Litbang Pertanian. Mengingat jumlah anggaran rutin yang tersedia adalah terbatas perlu dilakukan prioritas, artinya dalam satu tahun anggaran, tidak semua tenaga yang pindah dibayarkan biaya pindahnya. Pindahnya prioritas ini tergantung dari titik berat urgensinya, misalnya untuk tahap pertama diperlukan pemindahan tenaga yang mempunyai disiplin ilmu sosial ekonomi yang telah memiliki jenjang jabatan fungsional peneliti.

c. Detasering Pegawai

Untuk menambah tenaga sosial ekonomi pada BPTP/LPTP dengan cara pemidahan seperti diuraikan di atas, dapat pula ditempuh cara lain, seperti, memperbantukan untuk sementara tenaga peneliti sosial ekonomi pertanian yang terdapat pada balai penelitian dan letaknya berdekatan dengan lokasi BPTP/LPTP. Dalam kegiatan datasering perlu juga disusun rencana anggaran untuk para peneliti yang didetasir itu telah selesai untuk kegiatan maka yang bersangkutan akan kembali ke unit kerja asalnya. 
d. Rekruitmen Pegawai Baru

Untuk memenuhi kebutuhan jangka panjang dilakukan dengan perencanaan kebutuhan tenaga melalui pengadaan pegawai baru. Masalah yang paling utama dan kemungkinan akan dihadapi adalah keterbatasan jumlah informasi yang ada. Hal itu disebabkan keterbatasan jumlah informasi yang ada. Selain itu, disebabkan kebijakan Zerro Growth masih diberlakukan sampai saat ini sehingga jumlah formasi yang diterima masing-masing BPTP/LPTP seringkali tidak mencukupi dari kebutuhan yang ada. Untuk mengatasi hal itu, perlu adanya komitmen dari pimpinan badan Litbang Pertanian prioritas penggunaan formasi Badan Litbang Pertanian lebih diutamakan untuk memenuhi kebutuhan BPTP/LPTP terutama yang kondisi sumber daya manusianya sangat minimal. Untuk tingkat Badan Litbang Pertanian, dilakukan dengan cara mengurangi jatah informasi dari Balai/Loka Penelitian.

\section{PENUTUP}

\section{Simpulan}

1. Masalah pokok yang dihadapi adalah belum optimalnya pelaksanaan tugas dan fungsi BPTP/LPTP. Hal itu disebabkan masalah spesifik rendahnya jumlah tenaga yang mempunyai disiplin ilmu sosial ekonomi pertanian yang terdapat pada BPTP/LPTP.

2. Tercapainya peningkatan jumlah tenaga yang berdisiplin ilmu sosial ekonomi pertanian yang mencukupi, setelah dilakukan pengkajian akan dilaksanakan pemindahan tenaga sosial ekonomi pertanian dari Puslit/Puslitbang/Balit secara bertahap. Mengingat kemampuan untuk memenuhi biaya pindah sangat terbatas.

3. Mengatasi masalah keuangan tenaga pada BPTP/LPTP, selain dilakukan dengan cara pemindahan pegawai dapat juga dilakukan dengan cara datasering tenaga yang terletak pada unit kerja Balai/Loka penelitian yang berdekatan dengan lokasi BPTP/LPTP. Di samping itu, dapat juga dilakukan dengan cara merencakan formasi yang lebih banyak untuk BPTP/LPTP.

\section{DAFTAR PUSTAKA}

Keppres Nomor. 83 tahun 1993. Tentang Organisasi Departemen Pertanian Republik Indonesia.

Lembaga Administrasi Negara RI. 1994. Panduan Pola Kerja Terpadu.

1994. Sistem Administrasi Negara RI.

Rifai, A. Mien. "Kiat dan Instrumen Pengendalian Pengembangan Ristek dalam Sipteknas." Makalah Rakorna Ristek. 12-14 Agustus 1996 di Serpong.

Sekretariat Litbang Pertanian dan Tim Profesionalisme Tenaga Peneliti. "Pengelolaan Sumber daya Manusia Badan Penelitian dan Pengembangan Pertanian.” Makalah Rapat Kerja Badan Litbang Pertanian, 10-12 Maret 1997 di Denpasar, Bali. 
Siagian, S.P. 1987. Pengembangan Sumber Daya Insani. Jakarta: Gunung Agung.

SK. Mentan RI No. 96/Kpts/OT.210/2/1994 tanggal 11 Februari 1994 tentang Organisasi dan Tata Kerja Deptan.

SK. Mentan RI Nomor 798/Kpts/OT.210/12/1994 tanggal 13 Desember 1994 tentang Organisasi dan Tata Kerja Sama Balai Pengkajian Teknologi Pertanian dan Loka Pengkajian Teknologi Pertanian. 